\title{
Termos Numéricos e Qualificadores Geométricos na Língua Pangyjej do Povo Indígena Zoró
}

\author{
Numerical Terms and Geometric Qualifiers in the Pangyjej \\ Language of the Zoro Indigenous People
}

Samuel Zoró ${ }^{1}$

Kécio Leite ${ }^{2}$

Recebido em março de 2018

Aceito em maio de 2018

\section{Resumo:}

Este artigo apresenta resultados de uma pesquisa sobre termos numéricos e qualificadores geométricos na língua Pangyjej do povo indígena Zoró. A pesquisa foi realizada como trabalho de conclusão de curso na Licenciatura em Educação Básica Intercultural oferecida pelo Departamento de Educação Intercultural da Universidade Federal de Rondônia. Uma motivação para realização da pesquisa foi a ausência de materiais didáticos específicos sobre saberes matemáticos tradicionais nas escolas da Terra Indígena Zoró. O percurso metodológico envolveu registros fotográficos, entrevistas com professores e anciãos nas aldeias Anguj Tapua e Zawa Karej Pangyjej, observações de atividades diárias de roça, caça e pesca, além de diálogos informais com alunos da aldeia-escola Zawa Karej Pangyjej. Como resultados, foi possível registrar alguns termos numéricos e qualificadores geométricos referentes a saberes matemáticos na língua Pangyjej. Tais resultados poderão subsidiar a produção de materiais didáticos específicos para o ensino de matemática em escolas Zoró.

Palavras-chaves: Termos numéricos. Qualificadores geométricos. Língua Pangyjej. Zoró.

\begin{abstract}
:
This article presents results of a research on numerical terms and geometric qualifiers in the Pangyjej language of the Zoró indigenous people. The research was carried out as a conclusion course in the Undergraduate Degree in Basic Intercultural Education offered by the Intercultural Education Department of the Federal University of Rondônia. One motivation for conducting the research was the absence of specific didactic material on traditional mathematical knowledge in the schools of the Zoró Indigenous Land. The methodological path involved photographic records, interviews with teachers and elders in Anguj Tapua and Zawa Karej Pangyjej villages, observations of daily activities of hunting, hunting and fishing, as well as informal dialogues with students from Zawa Karej Pangyjej
\end{abstract}

\footnotetext{
${ }^{1}$ Professor indígena do povo Zoró. Licenciado em Educação Intercultural pela Universidade Federal de Rondônia.

${ }^{2}$ Doutor em Educação em Ciências e Matemática pela Universidade Federal de MatoGrosso. Professor do Departamento de Educação Intercultural da Universidade Federal de Rondônia-kecioleite@unir.br.
} 
school. As results, it was possible to register some numerical terms and geometric qualifiers referring to mathematical knowledge in the Pangyjej language. These results may support the production of specific didactic materials for the teaching of mathematics in Zoró schools.

Keywords: Numeric terms. Geometric qualifiers. Language Pangyjej. Zoró.

Breves considerações sobre os saberes tradicionais matemáticos nas escolas do povo Zoró.

A atual fase histórica da educação escolar indígena no Brasil possui marcos legais que garantem aos povos indígenas o direito a currículos, metodologias de ensino e materiais didáticos específicos, que respeitem suas particularidades linguísticas e culturais. Todavia, ainda existem poucos materiais didáticos que contemplem os saberes tradicionais, as culturas e as línguas de cada povo indígena na educação escolar oferecida às novas gerações.

No caso específico das escolas em comunidades do povo Zoró, que tem uma população de 621 pessoas (Ribeiro 2015), todas falantes da língua Pangyjej (família Mondé, tronco Tupí), e que habitam na Terra Indígena Zoró, município de Rondolândia-MT, ainda não existem materiais didáticos que contemplem os saberes matemáticos tradicionais do povo. Também não se observa interesse dos poderes públicos e ações governamentais para mudar essa realidade.

Para superar esta situação, faz-se necessário que os próprios professores indígenas realizem estudos e pesquisas, com apoio de suas comunidades, especialmente dos anciãos, para registrar os saberes tradicionais e organizar os dados para produção de materiais que possam ser usados em estudos com os alunos em sala de aula, visando valorizar a cultura, a língua e as tradições do povo.

Nesse contexto, o presente artigo apresenta resultados de uma pesquisa introdutória sobre termos numéricos e qualificadores geométricos na língua Pangyjej do povo indígena Zoró, realizada como trabalho de conclusão de curso na Licenciatura em Educação Básica Intercultural, oferecida pelo Departamento de Educação Intercultural da Universidade Federal de Rondônia.

A pesquisa teve por objetivo principal identificar saberes matemáticos do povo Zoró a partir da visão de anciãos e da observação de atividades cotidianas realizadas nas aldeias. Para tanto, buscou-se responder a seguinte questão de pesquisa: Quais são os saberes matemáticos tradicionais do povo indígena Zoró relacionados a quantificadores e qualificadores geométricos?

Apresentam-se a seguir a fundamentação teórica, o percurso metodológico da pesquisa e os principais resultados alcançados, seguidos de uma reflexão sobre a importância desses resultados para o início da organização e produção de materiais didáticos específicos para o ensino de matemática em escolas da Terra Indígena Zoró. 


\section{Educação escolar indígena e etnomatemática}

A educação é um processo comum a todas as sociedades humanas. Ela possibilita a reprodução ou alteração de aspectos culturais e sociais de cada povo ao longo do tempo (Brandão 2007). A educação escolar, por sua vez, tem suas particularidades e nem sempre existiu em todas as sociedades humanas. Entre os povos indígenas do Brasil, a escola como instituição educativa foi introduzida pelos colonizadores europeus e serviu a diversos propósitos ao longo dos últimos cinco séculos. Nesse sentido, a educação escolar oferecida ou imposta aos povos indígenas já esteve a serviço desde a catequização e a aculturação até a integração forçada de diferentes povos à sociedade ocidental colonizadora (Freire 2004, Ferreira e Silva 2007).

Apenas no final do século XX a educação escolar entre povos indígenas brasileiros ganhou novos marcos legais, possibilitando o reconhecimento de especificidades culturais, linguísticas e epistemológicas que permeiam a educação escolar em contextos indígenas. Surge assim o que se convencionou chamar de educação escolar indígena diferenciada, específica, intercultural e, dependendo do contexto sociolinguístico, bilingue.

A partir dessa reconfiguração historicamente recente das características que devem permear as escolas indígenas, abriu-se espaço para se repensar os processos pedagógicos, os currículos, a formação de professores e a produção de materiais didáticos específicos para a educação escolar indígena, levandose em consideração sempre as particularidades culturais e linguísticas de cada povo.

Do ponto de vista epistemológico, que diz respeito à natureza do conhecimento, suas origens e seu desenvolvimento, atualmente busca-se introduzir nos currículos das escolas indígenas, além dos conhecimentos ocidentais necessários à sobrevivência de todos os povos na contemporaneidade, os saberes específicos produzidos por cada povo ao longo de sua própria história, denominados de etnoconhecimentos.

No caso específico da referência aos saberes matemáticos tradicionais de cada povo ou grupo socioculturalmente identificável, tem sido utilizado o conceito de etnomatemática, entendida como "a matemática praticada por grupos culturais, tais como comunidades urbanas e rurais, grupos de trabalhadores, classes profissionais, crianças de um certa faixa etária, sociedades indígenas, e tantos outros grupos que se identificam por objetivos e tradições comuns" (D’Ambrosio 2011: 9).

A partir desse conceito de etnomatemática, reconhece-se teoricamente que cada povo, indígena ou não indígena, tem sua própria maneira de produzir, organizar e expressar os conhecimentos matemáticos, marcados e vivenciados em suas relações cotidianas (D'Ambrosio 2011; Fantinato 2009; Freitas e Ruiz 2011; Beltrão e Mastop-Lima 2009). Isso implica dizer que a matemática, tal 
como é convencionalmente ensinada na escola, não é universal, pois os saberes matemáticos de cada povo podem variar de acordo com os contextos, os usos, as cosmologias e até mesmo as línguas em que tais conhecimentos são formulados e se desenvolvem.

Daí o motivo pelo qual, em se tratando do ensino de matemática em escolas indígenas, deve-se contemplar também no currículo escolar e nos materiais didáticos os conhecimentos matemáticos historicamente construídos e utilizados pelos próprios povos indígenas, reconhecendo-os como parte do patrimônio cognitivo da humanidade, conforme preconiza o Referencial Curricular Nacional para as Escolas Indígenas (Brasil 1998).

Conforme D'Ambrosio (2011), isso significa reconhecer que cada sociedade tem uma maneira muito específica de entender as formas e os espaços, de contar e manejar quantidades, de lidar com medidas e calendários. Por isso, ressaltase a importância de que, na educação escolar indígena, o ensino de matemática deva partir do contexto, valorizando os conhecimentos tradicionais dos alunos, para só então apresentar outras formas de conhecimentos e conteúdos.

No caso específico do ensino de matemática, mudanças na educação escolar indígena estão sendo induzidas por diferentes ações em andamento em âmbito nacional, tais como cursos de formação de professores indígenas em nível médio e em nível superior com abordagens interculturais, debates teóricos e pesquisas em cursos de pós-graduação e organização de materiais didáticos bilingues (Suruí e Leite 2018).

Nesse sentido, conforme Costa, Ghedin e Souza Filho (2012), é necessário que a educação escolar compreenda e valorize os processos cognitivos mobilizados na confecção de cestarias e flechas, construção de malocas, pintura corporal, como elementos de orientação da educação matemática na escola indígena, de modo que estudantes indígenas possam dispor de maior compreensão da matemática ensinada na escola, que passa a fazer mais sentido e a ter mais significado.

Tomando estes pressupostos teóricos como base, a pesquisa foi desenvolvida, assumindo-se desde o início, conforme apontado na literatura sobre etnomatemática, que todos os povos, ao longo de suas histórias particulares, produziram conhecimentos matemáticos específicos. Tais conhecimentos surgiram como resposta às necessidades cotidianas de sobrevivência e se revelam por meio das técnicas, construções, produções materiais e nas diferentes línguas em que foram formulados.

\section{Percurso metodológico da pesquisa}

A pesquisa foi realizada nas aldeias Anguj Tapua e Zawã Karej Pangyjej, durante os anos de 2016 e 2017, por meio de entrevistas e registros com pessoas mais experientes e conhecedoras da cultura Zoró. Também através de observação 
de práticas pedagógicas realizadas por professores indígenas da Escola Estadual Indígena Zawã Karej Pangyjej, em parceria com os orientadores da cultura, que têm o papel junto à escola de orientar a aplicação de ensinamentos dos aspectos culturais enquanto conteúdo escolar, conforme previsto no Projeto Político Pedagógico das escolas do povo Zoró.

Para atingir o objetivo geral, que era pesquisar saberes matemáticos do povo Zoró a partir da visão de anciãos e da observação de atividades cotidianas realizadas nas aldeias, realizou-se inicialmente um estudo teórico de referenciais que tratam de etnomatemática, cultura e educação escolar indígena. Em seguida, fez-se a coleta de dados por meio de entrevistas e registros de saberes a partir de observações dos afazeres de membros das comunidades em atividades do cotidiano das aldeias, em espaços tradicionais como roça, caça e pesca, e também na escola, por meio das atividades de professores e orientadores da cultura. Os principais sabedores entrevistados foram Panderewup Zoró, cacique geral do povo Zoró, Manoel Thoathore Zoró, cacique da aldeia Anguj Tapua, e Valdo Pewanjura Zoró.

Como um recorte dos resultados da pesquisa, apresentam-se neste artigo os termos numéricos e os qualificadores geométricos identificados na língua Pangyjej, com alguns exemplos de frases de contextualização. Para apresentação, os dados foram organizados em quadros, com os registros realizados na língua Pangyjej e em português.

\section{Saberes matemáticos do povo Zoró}

Tradicionalmente o povo Zoró era monolíngue, falava apenas a língua Pangyjej, do tronco Tupí, da família Mondé. Ainda hoje, essa é a principal língua falada pelos membros do povo. Com o advento do contato, ocorrido em 1977, introduziu-se a língua portuguesa como segunda língua, que passou a ser ensinada às novas gerações principalmente por meio da educação escolar implantada nas aldeias. Juntamente com a língua portuguesa, e valendo-se desta como suporte, foram introduzidos por meio da escola conhecimentos e saberes que não pertenciam à cultura zoró.

Entre estes novos conhecimentos, encontram-se os de natureza matemática, como o sistema decimal de contagem, o sistema de numeração com algarismos romanos e indu-arábicos, sistemas de medida e o sistema monetário. Tais conhecimentos matemáticos introduzidos pela escola entre os Zoró, embora necessários à sobrevivência na contemporaneidade, não tiveram origem na história do desenvolvimento cultural do próprio povo anterior ao contato, e apresenta a tendência de substituir, ao longo do tempo, os conhecimentos matemáticos tradicionais zoró.

Um reflexo dessa substituição é a mudança provocada no léxico da língua Pangyjej, entendido como o conjunto dinâmico de todas as palavras e expressões 
que compõem a língua, aberto e suscetível às influências da língua portuguesa após o advento do contato com a sociedade não indígena e a introdução da educação escolar nas aldeias. Assim, passa a ser cada vez mais comum ouvirem-se palavras e expressões em português nas rodas de conversa e em outras situações de conversação sempre que o assunto envolve conteúdos de natureza matemática.

Para além da problemática sociolinguística envolvida neste fenômeno, por vezes compreendido como empréstimo linguístico, evolução histórica das línguas e outros conceitos correlatos, há uma situação epistemológica de fundo que não deve ser desconsiderada nos contextos das línguas indígenas. É fundamental considerar que a língua não está descolada de uma visão de mundo e dá suporte a uma epistemologia específica do povo que a produz e a utiliza. Nesse sentido, a língua Pangyjej está na base da epistemologia zoró, relacionando-se fortemente com a gênese e o desenvolvimento de ideias matemáticas tradicionais do povo, que já existiam em períodos anteriores à chegada do colonizador e à introdução do ensino de matemática escolar às novas gerações.

Assim, ao longo do desenvolvimento desta pesquisa, por meio de observações e de entrevistas, foram identificadas algumas ideias e alguns conceitos matemáticos tradicionais do povo Zoró existentes na língua Pangyjej. Os resultados são apresentados a seguir, organizados em quadros temáticos por categoria, registrados na língua Pangyjej e em português.

Quanto aos termos numéricos, foram identificados na contagem de objetos e animais até vinte, conforme Quadro 1 abaixo. Segundo os sabedores entrevistados, seria possível contar quantidades maiores na língua Pangyjej, aspecto a ser melhor investigado em uma futura pesquisa.

Quadro 1 - Termos numéricos na língua Pangyjej

\begin{tabular}{|l|l|}
\hline \multicolumn{1}{|c|}{ Pangyjej } & Português \\
\hline Muj & Um \\
\hline Busyt & Dois \\
\hline Baj birip & Três \\
\hline Ãsanu pira man & Quatro \\
\hline Muj pabe & Cinco \\
\hline Muj ma'ã ma pabe pi & Seis \\
\hline Busyt ma'ã ma pabe pi & Sete \\
\hline Baj birip ma'ã ma pabe pi & Oito \\
\hline Ãsanu pira man ma'ã ma pabe pi & Nove \\
\hline Pambabe supup & Dez \\
\hline Muj ma'ã pambi pi & Onze \\
\hline
\end{tabular}




\begin{tabular}{|l|l|}
\hline \multicolumn{1}{|c|}{ Pangyjej } & Português \\
\hline Busyt ma'ã pambi pi & Doze \\
\hline Baj birip ma'ã pambi & Treze \\
\hline Ãsanu pira man ma'ã pambi pi & Catorze \\
\hline Muj pi supup & Quinze \\
\hline Muj ma'ã ma pi pi & Dezesseis \\
\hline Busyt ma'ã ma pi pi & Dezessete \\
\hline Bajbirip ma'ã mapi pi & Dezoito \\
\hline Ãsanu pira man ma'ã ma pi pi & Dezenove \\
\hline Pambi supup & Vinte \\
\hline
\end{tabular}

Fonte: Banco de dados dos autores.

Estes termos numéricos em Pangyjej, principalmente quanto se referem a quantidades maiores que dez, são de pouca compreensão e uso pelos falantes jovens e crianças, que estão utilizando praticamente apenas os termos numéricos em português. Assim, é comum se ouvir dos alunos na escola, ou dos jovens em atividades cotidianas, mesmo quando estão falando em Pangyjej, expressões em português para se referirem a quantidades numéricas e a contagens.

Verifica-se assim não só uma diferença linguística, mas também de conteúdo entre as gerações, quanto ao domínio de conhecimentos matemáticos tradicionais. Incide sobre esse fenômeno a educação escolar, que se não for específica e diferenciada pode induzir tanto para o predomínio da língua portuguesa sobre a língua Pangyjej quanto para a colonização do saber matemático zoró pelo saber matemático ocidental, variando a intensidade desta colonização conforme a faixa etária dos membros do povo. Nesse sentido, entre os sabedores e membros mais velhos do povo, ainda é possível registrar nas conversações o uso dos termos numéricos em Pangyjej, conforme exemplos de frases ilustradas no Quadro 2 abaixo.

Quadro 2 - Frases de contextualização de termos numéricos na língua Pangyjej

\begin{tabular}{|l|l|}
\hline \multicolumn{1}{|c|}{ Pangyjej } & \multicolumn{1}{c|}{ Português } \\
\hline Zap'tig ma muj manga jap na & Zap'tig fez uma flecha \\
\hline Panderewup ma busyt bilip igia & Panderewup pegou dois peixes \\
\hline Mangaj ma baj biryp manga ini na & Minha mãe teceu três redes \\
\hline Asamu piraman ap tete anga um & Eu tenho quatro flechas \\
\hline $\begin{array}{l}\text { Roberto ma muj pabe ej igi kulerej } \\
\text { na }\end{array}$ & $\begin{array}{l}\text { Roberto foi pescar e pegou cinco } \\
\text { pintados }\end{array}$ \\
\hline $\begin{array}{l}\text { Valdo ma muj ma'ã ma pabe pi } \\
\text { mana p manga jap na bebej akap na }\end{array}$ & $\begin{array}{l}\text { Valdo fez seis flechas para caçar } \\
\text { porco do mato }\end{array}$ \\
\hline
\end{tabular}




\begin{tabular}{|l|l|}
\hline \multicolumn{1}{|c|}{ Pangyjej } & \multicolumn{1}{c|}{ Português } \\
\hline $\begin{array}{l}\text { Joana má ka ga kuj busyt ma'ã ma } \\
\text { pabe pi man a igi xibuja }\end{array}$ & $\begin{array}{l}\text { Joana foi à roça e pegou sete man- } \\
\text { diocas para comer com peixe assado }\end{array}$ \\
\hline $\begin{array}{l}\text { Marcelo ma baj birip ma'ã ma pabe } \\
\text { pi maj igi bulipwej na }\end{array}$ & $\begin{array}{l}\text { Marcelo colocou a rede de pesca no } \\
\text { rio e pegou oito peixes }\end{array}$ \\
\hline
\end{tabular}

Fonte: Banco de dados dos autores.

Quanto às noções matemáticas envolvidas em operações com quantidades, encontram-se também na língua Pangyjej expressões que remetem a uma lógica de operações matemáticas. Exemplos destas expressões foram registradas na pesquisa e estão apresentadas no Quadro 3 abaixo.

Quadro 3 - Operações matemáticas na língua Pangyjej

\begin{tabular}{|l|l|}
\hline Pangyjej & \multicolumn{1}{|c|}{ Português } \\
\hline Ma'gi & Subtrair \\
\hline Mamanka & Aumentar \\
\hline Kamã & Contar \\
\hline Paliri & Dividir \\
\hline Bagawa & Repartir \\
\hline Mangubu & Somar/juntar \\
\hline Xixin'tigi & Diminuir \\
\hline
\end{tabular}

Fonte: Banco de dados dos autores.

Quanto aos qualificadores geométricos, foram registradas durante a pesquisa palavras e expressões em Pangyjej que se referem tanto aos espaços e às formas dos invólucros (cascas) de objetos da natureza, quanto ao tipo de superfície de folhas, partes de animais, troncos de árvores e figuras planas presentes nos artesanatos e construções, conforme apresentado no Quadro 4 abaixo.

Quadro 4 - Qualificadores geométricos na língua Pangyjej

\begin{tabular}{|l|l|}
\hline Pangyjej & Português \\
\hline Xixin & Fino \\
\hline Puj & Grosso \\
\hline Sere & Raso \\
\hline Buligun & Fundo \\
\hline Tatu & Alto \\
\hline Guj kuj & Baixo \\
\hline Puj & Grande \\
\hline Xixin & Pequeno \\
\hline
\end{tabular}




\begin{tabular}{|l|l|}
\hline Pangyjej & Português \\
\hline Pag & Aberto \\
\hline Puga & Fechado \\
\hline Pule & Redondo \\
\hline Ximabywal & Chato \\
\hline Tatu & Comprido \\
\hline Kawã & Curto \\
\hline Abimi & Reto \\
\hline Kanjãm & Torto \\
\hline Iri'kaawni & Plano \\
\hline
\end{tabular}

Fonte: Banco de dados dos autores.

A construção de malocas, a confecção de artesanatos e a pintura corporal são momentos privilegiados para observação do uso de qualificadores geométricos na língua Pangyjej. Formas geométricas representadas por figuras planas são nomeadas e ganham significados próprios em cada um desses momentos.

$\mathrm{Na}$ confecção de flechas e nos trançados dos artesanatos, surgem padrões geométricos que servem tanto para o bom funcionamento dos objetos quanto para sua ornamentação. A aerodinâmica das flechas depende da simetria das penas e da distribuição dos pesos entre a base e a ponta. Por sua vez, os trançados de palha para confecção de balaios, esteiras, paneiros e cestos estão diretamente relacionados com a resistência para carregamento de cargas ou para armazenamento de alimentos e outros materiais. Assim, em todos os casos, existe uma relação direta entre a forma geométrica dos objetos, a utilidade e a finalidade dos mesmos, complementada com uma função estética.

A Figura 1 abaixo mostra os padrões geométricos de flechas zoró, confeccionadas por homens e ornamentadas com pelos de porcão do mato e penas. Por sua vez, a Figura 2 é um registro da confecção de trançados de palha por mulheres zoró.

Figura 1: Ornamentação e padrões geométricos de flechas confeccionadas por homem zoró. Fonte: Banco de dados dos autores.

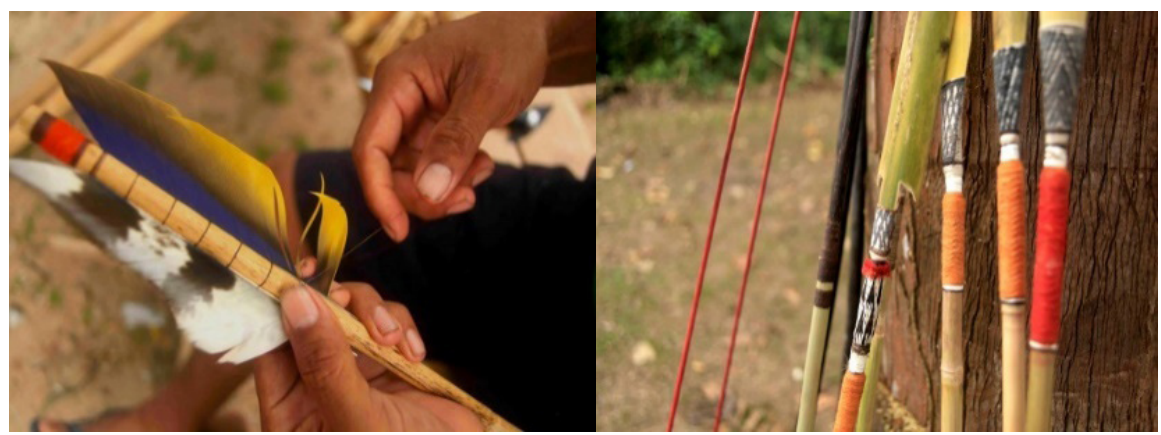


Figura 2: Mulheres zoró confeccionam trançados de palha com padrões geométricos. Fonte: Banco de dados dos autores.

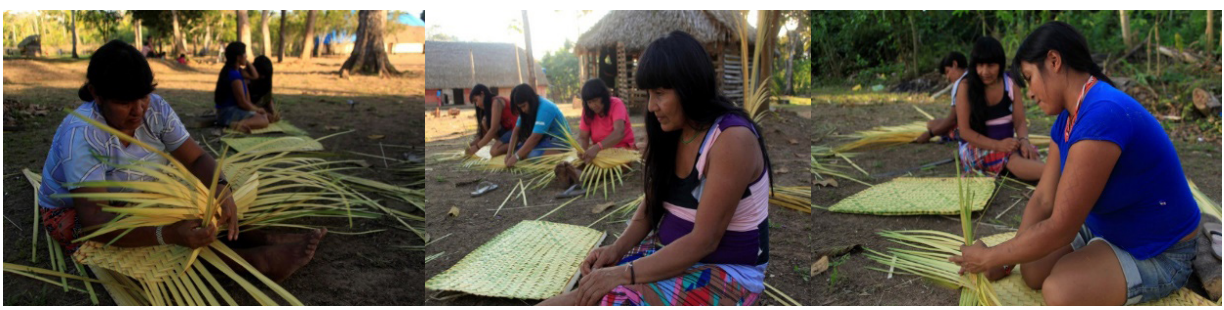

No caso da construção de malocas, cada parte da construção recebe um nome em Pangyjej, de acordo com seu formato geométrico, correspondendo aos nomes de figuras geométricas planas em português, conforme apresentado no Quadro 5 abaixo.

\section{Quadro 5 - Formas geométricas planas na língua Pangyjej}

\begin{tabular}{|l|l|}
\hline \multicolumn{1}{|c|}{ Pangyjej } & Português \\
\hline Bambekatawa & Círculo \\
\hline Gurê & Triângulo \\
\hline Zap patã & Linha reta \\
\hline Gajawamam & Curva \\
\hline Bibe tikyp & Losango \\
\hline Akape & Trapézio \\
\hline
\end{tabular}

Fonte: Banco de dados dos autores.

Outros qualificadores geométricos existentes na língua Pangyjej não possuem correspondentes entre os nomes dados a figuras planas em português, porque se referem a formas específicas de insetos e outros animais, tais como tatu, jabuti, cobra e onça. São exemplos os nomes de pinturas corporais inspiradas em formas geométricas da natureza: Amuã wesut (forma do casco do jabuti), Baj kiryp wesua (forma das escamas da cobra pico de jaca), Baj baj yt (forma do movimento das cobras), Wanzuj sabe kap (forma do casco do tatu), Bulip kussalap (forma da guelra dos peixes), Mandega abitega abe wesu (forma do dorso da lagarta do tronco da árvore abia).

Observa-se portanto que os qualificadores geométricos na língua Pangyjej não são simples abstrações ou termos linguísticos de um pensamento matemático desconectado da realidade concreta da existência do povo. O pensamento geométrico zoró mostra-se intimamente relacionado às formas presentes na natureza da região em que o povo vive, à floresta, aos animais e às plantas. Daí o motivo pelo qual as pinturas corporais, as produções materiais como flechas, trançados de palhas e adornos por vezes buscam imitar e representar estas formas geométricas da natureza. 
Tal constatação está de acordo com a perspectiva teórica de que a matemática se apresenta como uma construção humana, inserida em processos históricos e culturais. Assim, o pensamento matemático não possui uma única forma em toda a humanidade, visto que as sociedades humanas se desenvolveram em distintos ambientes, valendo-se de diferentes recursos da natureza para a sobrevivência e para a produção de seus patrimônios culturais materiais e imateriais.

A especificidade linguística é uma marca do conhecimento matemático zoró e ilustra também a concepção de que a representação, a composição e a comunicação dos conhecimentos matemáticos variam entre diferentes línguas, contrariando a tese da universalidade da matemática ocidental tradicionalmente ensinada na escola. Nesse sentido, conforme Medeiros e Miranda (2009), diferentes estratégias linguísticas podem ser utilizadas para expressar conhecimentos matemáticos em diferentes línguas, incluindo-se nomes, adjetivos, advérbios, combinações sintáticas de nomes, reduplicação de temas nominais e verbais e reduplicação de partículas.

A própria estrutura dos sistemas de contagem varia entre culturas e línguas distintas. Nesse sentido, conforme Green (2002) e Ferreira (1998), entre os povos indígenas do Brasil já se identificaram sistemas numéricos de base um, dois, três, cinco, dez e vinte, com processos de raciocínio específicos, uns mais holísticos e outros mais analíticos.

Assim, como continuidade e desdobramento da presente pesquisa, outros estudos serão realizados, visando um aprofundamento da compreensão de aspectos linguísticos, epistemológicos e de visão de mundo que permeiam os conhecimentos matemáticos do povo Zoró, suas especificidades culturais e suas potenciais contribuições para o ensino de matemática às novas gerações por meio da educação escolar.

\section{Considerações finais}

Os resultados dessa pesquisa apontam para a existência de uma etnomatemática zoró, composta de conhecimentos matemáticos expressos na língua Pangyjej, relacionados a termos numéricos e qualificadores geométricos que se revelam em situações cotidianas e na elaboração de objetos da cultura material, tais como confecção de paneiros, cestos, construção de casas (maloca), confecção de flechas e pintura corporal.

Foi possível identificar uma diferença no uso da língua entre jovens e velhos, sendo que os primeiros tendem a usar termos numéricos em português, mesmo quando estão conversando em Pangyjej. Isso indica a influência da língua portuguesa sobre a língua Pangyjej, iniciada com o contato ocorrido em 1977, e põe em destaque o papel da educação escolar para o fortalecimento da língua e dos conhecimentos do povo Zoró.

A ausência de materiais didáticos específicos nas escolas do povo Zoró é um 
desafio a ser superado na direção de uma educação escolar indígena diferenciada e intercultural. Nesse sentido, os resultados dessa pesquisa poderão fornecer subsídios para o início da elaboração de materiais para o ensino de matemática na língua Pangyjej que contemplem os conhecimentos matemáticos tradicionais do próprio povo.

\section{Referências}

Beltrão, J. F.; Mastop-Lima, L. (Orgs.). Matemáticas. No plural! Saberes matemáticos indígenas e sistema de aferição. Belém: IEMCI,2009.

Brandão, C. R. O que é educação. São Paulo: Brasiliense, 2007.

Brasil. Ministério da Educação. Referencial curricular nacional para as escolas indígenas. Brasília. 1998.

Costa, L. F. M.; Ghedin, E.; Souza Filho, E. A confecção de cestos e suas possibilidades pedagógicas para o ensino de matemática na escola indígena Ticuna. Educação Matemática Pesquisa, São Paulo, SP, v. 14, n. 1, p.105-125, 2012.

D’Ambrosio, U. Etnomatemática: elo entre as tradições e a modernidade. Belo Horizonte: Autêntica, 2011.

Fantinato, M. C. C. B. (Org.). Etnomatemática: novos desafios teóricos e pedagógicos. Niterói-RJ: Editora da UFF, 2009.

Ferreira, L. L.; Silva, A. A. A busca da autonomia no processo da educação escolar indígena. Cadernos de Educação Escolar Indígena, Barra do Bugres, MT, v. 5, n. 1, p. 57-63, 2007.

Ferreira, M. K. L. Madikauku: os dez dedos das mãos: Matemática e povos indígenas no Brasil. Brasília: MEC, 1998.

Freire, J. R. B. Trajetória de muitas perdas e poucos ganhos. In: Educação escolar indígena em Terra Brasilis: Tempo de novo descobrimento. Rio de Janeiro: IBASE.

Freitas, R. M. C.; Ruiz, M. A. S. 2011. Etnomatemática: Sistema de Numeração dos povos Indígenas do Alto Rio Negro no Estado do Amazonas. Anais do XV EBRAPEM, Campina Grande, 2004.

Green, D. Os diferentes termos numéricos das línguas indígenas do Brasil. In: Ferreira, M. K. L. (org.). 2002. Ideias matemáticas de povos culturalmente distintos. São Paulo: Global, 2002.

Medeiros, N. M. J.; Miranda, M. G. Análise preliminar dos quantificadores numéricos e não numéricos em Krenak (família Botocudo). Anais do VI Congresso Internacional da ABRALIN. p. 2669-2672. João Pessoa: Editora Ideia, 2009.

Ribeiro, T. M. (Org.). Terra Indígena Zoró. Porto Velho: Kanindé, 2015.

Suruí, A. P.; Leite, K. G. Etnomatemática e Educação Escolar Indígena no contexto do povo Paiter. Zetetiké, Campinas, SP, v. 26, n. 1, p. 94-112, 2018. 